\title{
Price and Yield As Sources of Variability of Farm Revenues in Transition Economies: The Case of Armenia
}

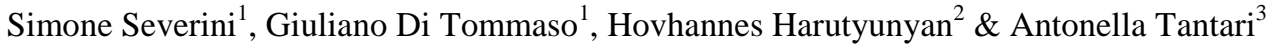 \\ ${ }^{1}$ Università della Tuscia - DAFNE, Viterbo, Italy. \\ ${ }^{2}$ Eurasia International University, Yerevan, Armenia. \\ ${ }^{3}$ CREA - Consiglio per la ricerca in agricoltura e l'analisi dell'economia agraria, Rome, Italy. \\ Correspondence: Simone Severini, Università della Tuscia - DAFNE, Via S. C. De Lellis snc, Viterbo, 01100 Italy.
}

Received: June 27, 2016

Accepted: July 15, 2016

Available online: August 19, 2016

doi:10.11114/aef.v3i4.1695

URL: http://dx.doi.org/10.11114/aef.v3i4.1695

\begin{abstract}
In transition economies, the shift to a market system has been accompanied by relevant evolutions of farm income level. Sustainability of farming depends not only on the level but also on the variability of economic results over time. Climatic changes and increasing market uncertainty make small-scale farmers particularly vulnerable to this.

This paper analyses revenue variability of the five main crops in Armenia and, by using variance decomposition, it assesses what portion of it is associated with prices and yields and whether a natural hedge exists. The analysis accounts for presence of trends in yield, price and revenue - a situation commonly encountered in transition economies.

Variability of revenues of single crops is high. While in some crops the variance associated with price exceeds that of yield, in other cases the opposite occurs. Policy and methodological insights regarding how to manage and to study revenue risk in transition economies are discussed.
\end{abstract}

Keywords: Farm revenue risk, market and climatic uncertainty, transition economies, variance decomposition, Armenia.

\section{Introduction}

The farm sector in Armenia, as well as in other transition economies, has shifted from a centrally planned system to an open market system undergoing profound structural changes. Indeed, the shift to a market system has been accompanied by a strong increase of productivity, high levels of inflation and fast and relevant evolutions of farm income level. The analysis of agricultural income is very important because it affects sustainability of farming and the wellbeing of population living in rural areas. For example, Kannan (2015) analysed changes in real income noticing that peasant suicides in Indian have also been explained by non-profitability of farming.

However, sustainability of farming depends not only on the level but also on the variability of farm economic performances over time (Hartaker et al. 2004). The fluctuation of economic performances can affect farmers' well-being and decisions, their ability to expand operations and repay debt and, in turns, this can also have secondary effects on agribusiness firms and creditors (Mishra \& El-Osta 2001). Indeed, while farming has always been a risky business, it has become even more so in the current context of climatic change and increasing market uncertainty. Regarding the latter, the prices of agricultural commodities have been particularly unstable during the economic turbulence of the years 2006-08 (described, among others, by Baffes \& Haniotis, 2010). The riskiness of farming has made small-scale farmers, especially marginalized peasant producers, particularly vulnerable (Isakson 2015).

This calls for an increased attention to farm risk management and related tools. For example, financial derivatives have received a lot of attention specifically in transition economies where markets for such tools are still missing or are not fully functioning (Muradullaev et al. 2015; Bobojonov \& Götz 2015).

Such interest has been justified by the idea that producers in these countries are facing high fluctuations in farm revenues over time (due to both market and production uncertainty) and that the use of appropriate risk management tools (including agricultural insurances) can increase investments and spur agricultural modernization (Isakson 2015).

However, these claims are not always based on empirical evidences. In particular, analyses conducted in developing and 
transition economies that have systematically assessed the extent of farm revenue variability over time and the sources of such variability are missing. The former aspect is crucial because it aims at assessing whether revenue risk is really an issue and whether governments should intervene to help farmers in coping with it. The analysis of the sources of risk is also important provided that, if the variability is coming mainly from the variability of product prices or from the variability of production levels over time, farmers should use very different risk management strategies and tools (Hartaker et al. 2004).

This paper analyses revenue risk of the five most important crops in Armenia. It assesses the extent of such variability, which farm enterprises have the most variable revenues and which are the main sources of revenue variability. In particular, the variance of unitary revenues of a single crop is decomposed into price and yield components. This allows to show whether prices or yields are the most important components in generating such variability and if natural hedging (i.e. negative correlation between prices and yields) exists.

Addressing these issues has policy implications regarding the need for supporting risk management in the Armenian farm sector, on which crop productions to focus and whether tools to manage price risk or yield risk or both are needed.

The papers also aims at addressing some methodological issues including the following: when trends should be accounted for and how and how much results regarding level of variability and variance decomposition change when using detrended series.

All these policy and methodological issues appear to be potentially relevant not just for Armenia but also for other transitions economies. This is because in these countries the farm sector is facing revenue risk and looking for ways to cope with it and their farm sectors are characterized by positive trends in productivity and high levels of inflation.

Next section provides a short background on the analysis of variability of farm income and revenues while the following section explain data and methodology used in this analysis. After having presented and discussed the obtained empirical results, the last section provides some conclusions including policy recommendations and suggestions for further research on the considered topic.

Several are the risks affecting farm business but most of the emphasis is given by the literature on business risk (OECD 2009). This is generated by the aggregate effect of production, market and other sources of business specific risks (Hardaker et al. 2004). While many analyses have been focused on single farm risk sources (e.g. yield risk or price risk) or single production enterprises (e.g. milk production), it has been stated that what is relevant is the interaction between the many elements generating business risk (OECD 2009). This is clearly shown by the fact that the final and whole risk a farmer is facing depends, for example, on the interaction between the different production activities carried on and, within each one, between the evolutions of different parameters such as, in particular, product price and yield.

Empirical analyses on the stability of farm income over time are not many. Mishra and Sandretto (2002) investigate the stability of the aggregate income of US farmers considering also off-farm income, unfortunately this latter kind of data are hardly available.

In order to evaluate the overall business risk the farm sector is facing, it should be needed to account first of all for the variability of the farm income over time (Mishra \& Sandretto 2002; OECD 2009). However, income data are not always available particularly in developing countries. On the contrary, revenue data are often available. Considering that revenues is the main component of farm income, it seems worth to focus on this economic parameter if income data are not available. This is also particularly true when revenue data are disaggregated by single enterprises (i.e. revenues from different crops) and when revenue data allow for disaggregation between price and yield as it is the case in this analysis. This fortunate case allows for investigating which farm enterprises are responsible the most for the overall farm revenue variability and whether prices or yields are the main sources of such variability.

When the analysis is aimed at assessing the risk farmers are facing, this should be focused only on unexpected evolutions of the indicators of farm economic performance. However, "the determination of what type of behaviour constitutes instability is subjective, it is not possible to advocate unequivocally the use of any one measure." (Offutt \& Blandford 1986: 66). This is also the case of the treatment of trends because variability and instability are not necessarily equated. The measurement of instability requires that a judgement be made as to what constitutes "acceptable" vs. "unacceptable" variability. In the case a trend is present, it is often assumed that such trend can be predictable and does not therefore constitute instability. This provides a rationale for the exclusion of trend in assessing instability (Offutt \& Blandford 1986). However, "the treatment of trends is perhaps the paramount issue in the application of single variable measures. Whether or not trend is regarded as instability depends on the contest of the analysis and recognition of trend should always be made inasmuch as it influences a measures's empirical evaluation of data series. Commonly, some coefficient of variation is applied to the residual of a series net of trend" (Offutt \& Blandford 1986).

The problem is relevant because the way trends are accounted for affects the results of both the assessed level of 
variability and of the variance decomposition analysis. In particular, the use of detrended data has been found to reduce the error of the approximate formula for variance decomposition (Burt \& Finley 1968).

How to account for trends appears of paramount importance in analyzing variability in the farm revenues in Armenia but also in other transition economies because strong trends in both prices and yields have been found. Most of the observed increases in prices can be explained by the economic turbulence of the years 2006-08 (discussed, among others, by Baffes \& Haniotis, 2010) and by the inflation such countries have experienced in the last decades. In Armenia the strong positive trend in agricultural production affected the whole farm sector as well as the single farm industries and has been generated by the productivity growth generated by introduction of innovation and investments. (Figure 1). Similar evolutions are common in many other transition economies (Figures 2,3).

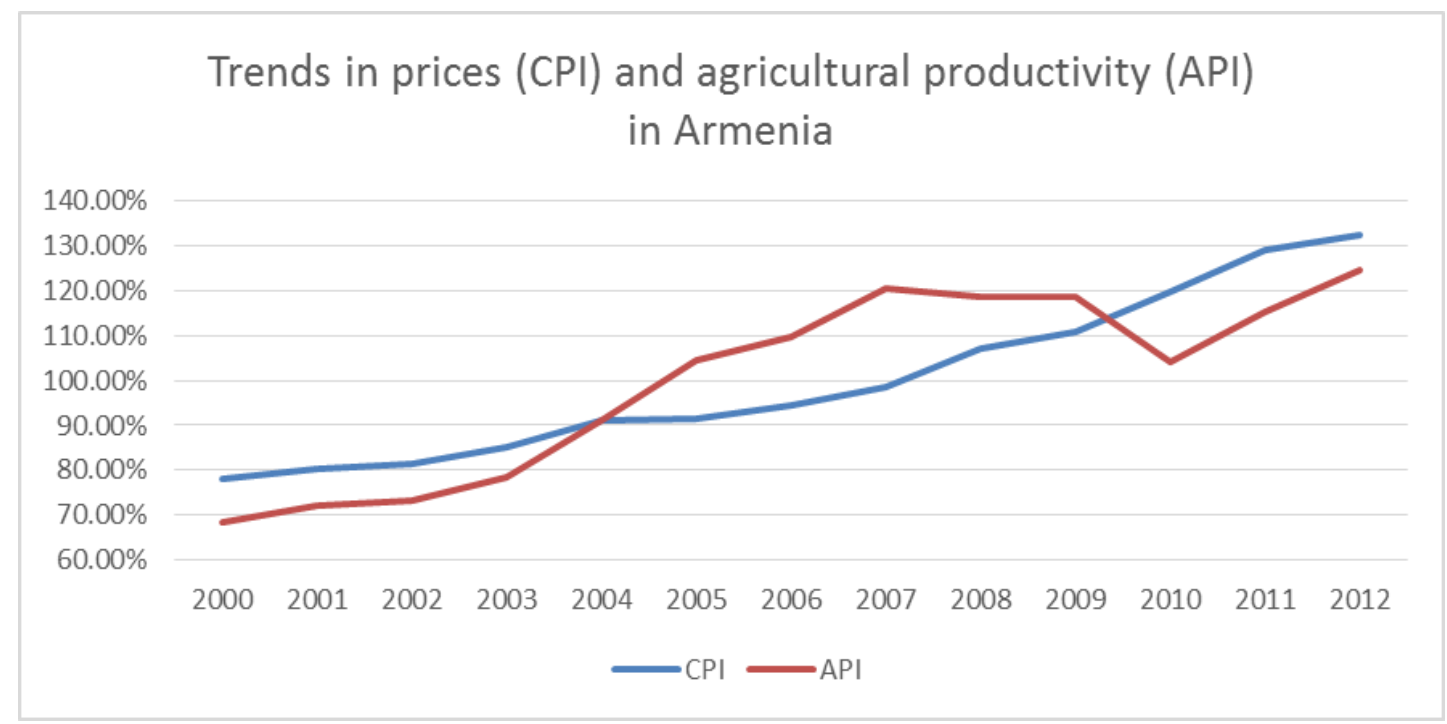

Figure 1. Trends of prices and agricultural productivity in Armenia. Consumer Price Index (CPI) and Agricultural Productivity Index (API). Standardized indexes (average values $=100$ ).

Source: Own elaboration on FAOSTAT and World Bank data.

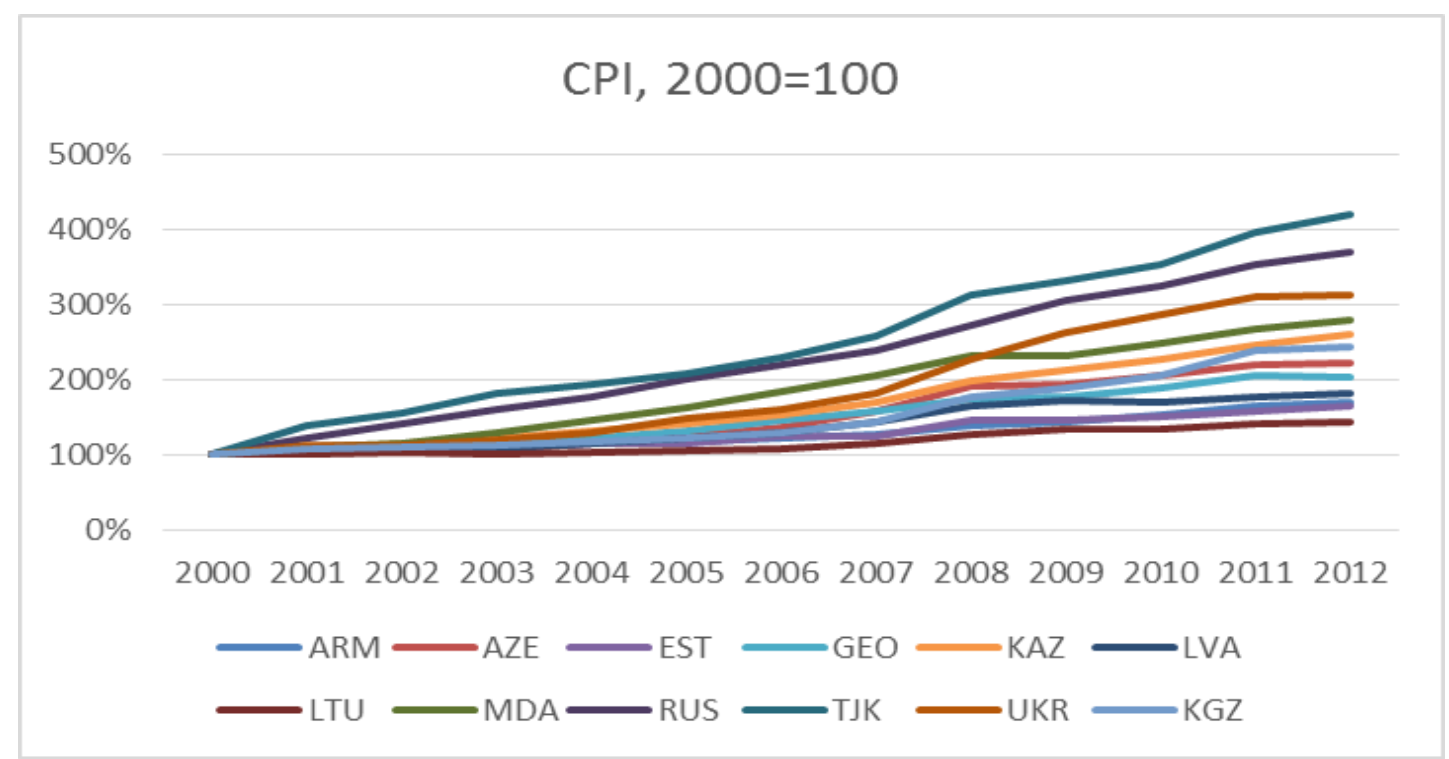

Figure 2. Evolution of prices in selected transition economies. Consumer Price Index (CPI).

Source: Own elaboration on FAOSTAT and World Bank data. 


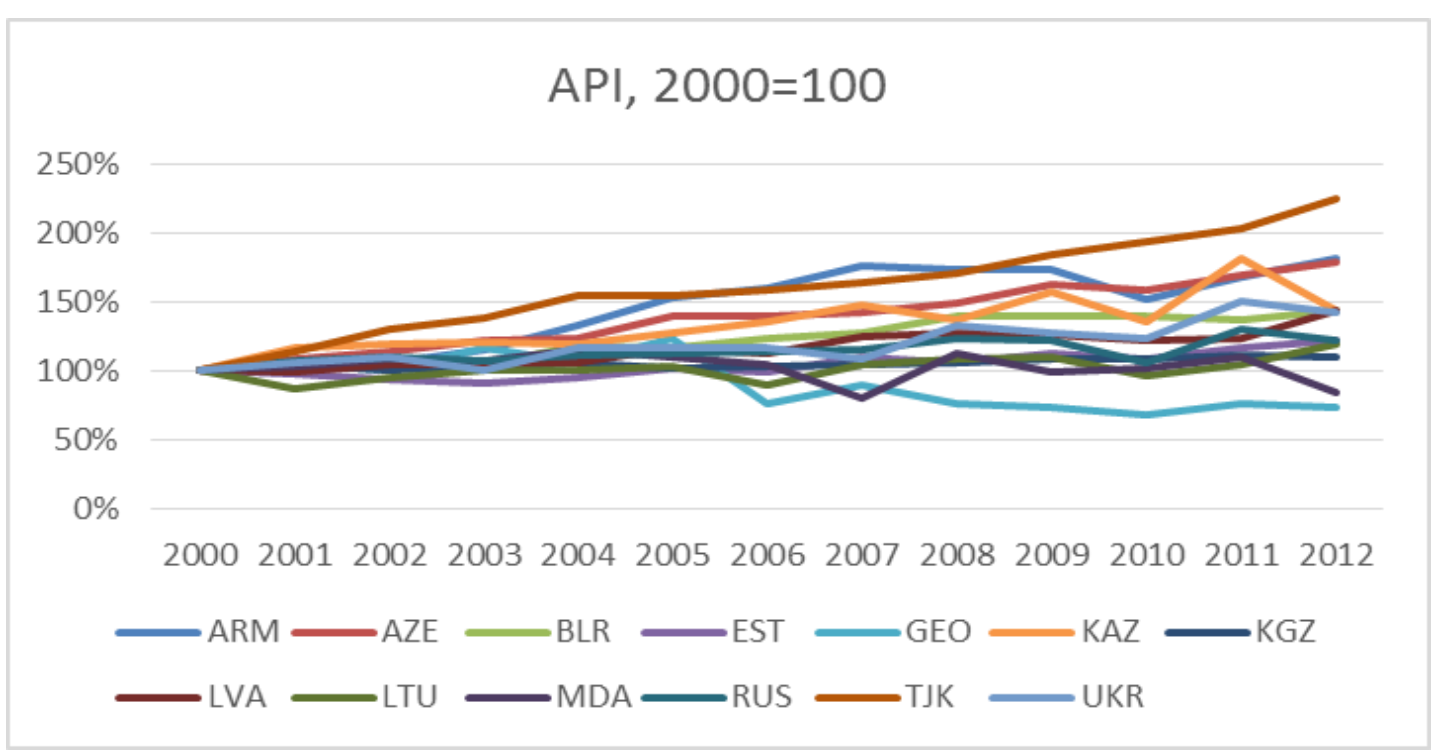

Figure 3. Evolution of agricultural productivity in selected transition economies. FAO Agricultural Production Index (API).

Source: Own elaboration on FAOSTAT and World Bank data.

\section{Method}

Data regarding revenues, harvested area, production levels for single crops and for the Agricultural Production Index (used as a productivity index) were obtained from UN Food and Agriculture Organization (FAO) statistics (http://faostat3.fao.org/). Data on the Consumer Price Index (CPI) in Armenia, used to deflate monetary data, are from World Bank.

The analysis refers to the whole country aggregate for the years 2000-2012, i.e. after the privatization process in the sector occurred. It focuses on the five crops that are the most relevant in terms of contribution to overall gross production value from the whole farm sector (GPV) (Table 1).

Table 1. Shares of gross production value of the farm sector generated by the considered five main crops in Armenia (Per cent of the revenues from all crops). Average over the period 2000 - 2012.

\begin{tabular}{cc}
\hline & Share (\%) \\
\hline Potatoes & 14.0 \\
Grapes & 7.1 \\
Wheat & 6.2 \\
Apples & 3.9 \\
Barley & 3.2 \\
Total of the previous crops & 34.4 \\
\hline Source: Own elaboration on FAOSTAT data.
\end{tabular}

The analysis focuses on the variability of unitary revenues obtained by dividing GPV in local currency by the harvested area (LCR/ha). For a specific crop, unitary revenues (UREV) is defined as:

$$
U R E V=P * Y
$$

Where $\mathrm{Y}$ refers to crop yield (t/ha) and $\mathrm{P}$ to average annual farm gate producer price (LCR/t).

Variability of UREV is assessed by means of Coefficients of Variation (CV) calculated over the considered 13-year period.

Several ways to identify trends can be used. Because variability analysis results are sensitive to trend choice, it should be based on both reasonable assumptions regarding the degree of knowledge of farmers and statistical analysis of the historical series.

Farmers may be assumed to have: 
i) knowledge regarding the general evolution of both prices in the whole economy (i.e. inflation rate) and productivity in agriculture (i.e. general trends for the whole farm sector);

ii) a more specialized knowledge regarding the evolution of prices and yields of the specific crops they produce (i.e. crop specific trends).

If farmers are assumed to be able to predict only the general evolution of prices in the economy, price series could be adjusted accounting for inflation only. In the analysis, price series have been deflated using the CPI. This means to assume that farmers are concerned with the variability of the following:

$$
U R E V^{\prime}=P^{\prime} * Y
$$

where UREV' and $\mathrm{P}^{\prime}$ indicated deflated values originated by using annual values of the deflator. This yields price constant (i.e. real) values for prices and unitary revenues.

Farmers may also be assumed to predict the general evolution of productivity in the agricultural sector. In particular, the series of the Agricultural Production Index (API) calculated by FAO for Armenia show a clear positive trend during the considered period. Under these circumstances, it seems very appropriate to adjust yield series accounting for the general evolution of productivity. This suggested to adjust the original series using the fitted values of API, yielding the following measure of unitary revenues:

$$
U R E V_{G}^{\prime}=P^{\prime} * Y_{G}
$$

where $Y_{G}$ indicates the original yield series divided by the fitted values (standardized with mean $=1$ ) of API.

Linear and exponential trends have been estimated by Ordinary Least-Squares. Estimation results have been interpreted in order to assess whether a significant trend exists (Note 1).

If farmers are assumed to be able to predict the evolution of the yield of the specific crops they produce, it is needed to estimated crop-specific trends in yields obtaining the following:

$$
U R E V^{\prime}{ }_{C}=P^{\prime} * Y_{C}
$$

where $\mathrm{Y}_{\mathrm{C}}$ indicates the original yield series adjusted using indexes based on the fitted values of trends of the yield for the specific crop under investigation. UREV'C indicates the resulting adjusted unitary revenues.

Finally, the original series for UREV have been also detrended using the Ordinary Least-Squares approach proposed by Hadrich (2013):

$$
y_{t}=T \beta+e_{t}
$$

where $\mathrm{T}$ represents time with $\mathrm{t}=2000, \ldots, 2012$. To normalize revenue, the residuals were added to the average revenue value $(\bar{y})$ such that:

$$
\widehat{y_{t}}=\bar{y}+\widehat{e_{t}}
$$

where $\widehat{y_{t}}$ can be named $\mathrm{UREV}_{\mathrm{C}}$. It is important to underline that UREV' ${ }_{C}$ and $\mathrm{UREV}_{\mathrm{C}}$ do differ because, in the first case, trends are estimated on the yield series only (and prices are deflated). In the latter case, trends are estimated on the original UREV series, so that trends account at the same time for the evolution of both prices and yields. UREV $\mathrm{C}_{\mathrm{C}}$ series are not going to be used in the variance decomposition analysis.

The role of the components price and yield on unitary revenue variability is assessed by applying the variance decomposition by sources, originally proposed by Goodman (1960) and Bohrnstedt and Goldberger (1969), that relies on multiplicative identities and applied in empirical analyses in the area of agricultural economics (Burt \& Finley 1968; El Benni \& Finger 2013; Hadrich 2013; Mishra et al. 2002; Wolf et al. 2009). It is worth mentioning that all these empirical analyses have been focusing in developed countries such as the USA and Switzerland even if farm risk management is extremely important in developing countries too.

In the case of multiplicative identities $\left(y=x_{1} \cdot x_{2}\right)$ (e.g. unitary revenue as the product of price and yield), the variance of the resulting variable (y) has been written by Burt and Finley (1968) in terms of the following Taylor's series expansion:

$$
\begin{gathered}
\operatorname{Var}(y)=\mu_{2}^{2} \operatorname{Var}\left(x_{1}\right)+\mu_{1}^{2} \operatorname{Var}\left(x_{2}\right)+2 \mu_{1} \mu_{2} \operatorname{Cov}\left(x_{1}\right)\left(x_{2}\right)+E\left[\left(x_{1}-\mu_{1}\right)\left(x_{2}-\mu_{2}\right)-\operatorname{Cov}\left(x_{1}, x_{2}\right)\right]^{2}+ \\
2 \mu_{1} E\left(x_{1}-\mu_{1}\right)\left(x_{2}-\mu_{2}\right)^{2}+2 \mu_{2} E\left(x_{1}-\mu_{1}\right)^{2}\left(x_{2}-\mu_{2}\right)
\end{gathered}
$$

where $\mu_{1}$ and $\mu_{2}$ denote the means of $x_{1}$ and $x_{2}$. 
The first two terms are the direct effects of $\mathrm{x}_{1}$ and $\mathrm{x}_{2}$, and the third term is a first order linear interaction effect. The fourth term is the variance of the covariance product about the covariance parameter, is necessarily positive and is neutral for purposes of interpretation. The last two terms are higher-order interaction effects (Burt \& Finley 1968).

Using the asymptotic approximation allows to consider only the first three terms. Dividing such terms by the sum of the first two terms leads to the standardized form proposed by Burt and Finley (1968):

$$
\frac{\mu_{2}^{2} \operatorname{Var}\left(x_{1}\right)+\mu_{1}^{2} \operatorname{Var}\left(x_{2}\right)+2 \mu_{1} \mu_{2} \operatorname{Cov}\left(x_{1}\right)\left(x_{2}\right)}{\mu_{2}^{2} \operatorname{Var}\left(x_{1}\right)+\mu_{1}^{2} \operatorname{Var}\left(x_{2}\right)}=p_{1}+p_{2}+p_{12}
$$

where each term in the latter expression is the respective numerator divided by the denominator in the fraction written above. Both $\mathrm{p}_{1}$ and $\mathrm{p}_{2}$ are positive and sum to unity while the interaction (or covariance) effect $\mathrm{p}_{12}$ can be of either sign.

This variance decomposition approach has been applied to original data (1) as well as to data treated for trends $(2,3,4)$. This allows to verify whether and how much detrending causes a relevant reduction in the error of the approximate formula as it has been shown by Burt and Finley (1968).

Regarding the detrending approach, it is worth mentioning that using (2) and (3) corresponds to use the same adjustment to all crops. This is expected to preserve the nature of the additive revenue identity $\left(y=\sum_{i} x_{i}\right)$. This is a relevant aspect provided that the variance decomposition approach has been used to assess the contribution of each of the five considered crops to the variability of the revenues from the whole crop sector. This leads to the well-known formula:

$$
\operatorname{Var}\left(\sum_{i}^{n} x_{i}\right)=\sum_{i}^{n} \operatorname{Var}\left(x_{i}\right)+2 \sum_{i}^{n} \sum_{j}^{n} \operatorname{Cov}\left(x_{i}, x_{j}\right)
$$

This analysis is aimed at assessing which of the considered crops are the most important in generating the variability of the overall crop revenue.

\section{Results}

A strong positive trends exists in the evolution of unitary revenues (UREV) in all considered five crops (Table 2).

This is clearly the case because of the presence of significant positive trends in prices and yields. Trends in prices are positive and significant at 5 per cent in all five crops. Significant positive trends exists for the yields of grapes, barley and potatoes (at 1 per cent).

These results clearly ask for accounting for such trends in order to avoid overestimation of the variability of UREV.

Trends can be accounted considering inflation (for prices) and the evolution of productivity over time (for yields). The high correlation coefficients between crop prices and the Consumer Price Index (Table 2) suggest that deflating the price series could be a good approach to account for price trends. This is also supported by the fact that no residual significant trends can be estimated on deflated price series.

For yield series, trends can be accounted for by considering the evolution of productivity in the whole agricultural sector (by using the trend of the FAO API) or crop specific yield trends. Significant crop specific trends can be estimated only for three of the considered crops provided that for wheat and apples the trend coefficients are significant only at 10 per cent (Table 2). Furthermore, the evolution of the yields of all considered crops but wheat is strongly correlated with the evolution of the API (Table 2).

These findings support the idea that, before assessing the variability of UREV and decomposing such variability, data should be adjusted to account for trends. Furthermore, deflating the price series and using the trend in the API index could be a reasonable approach to account for the trend in prices and yields, respectively. 
Table 2. Correlations and trends in the original series of unitary revenues (UREV), prices (P) and yields (Y) in wheat, grapes, barley, potatoes and apples in Armenia. National annual data in the years $2000-2013$.

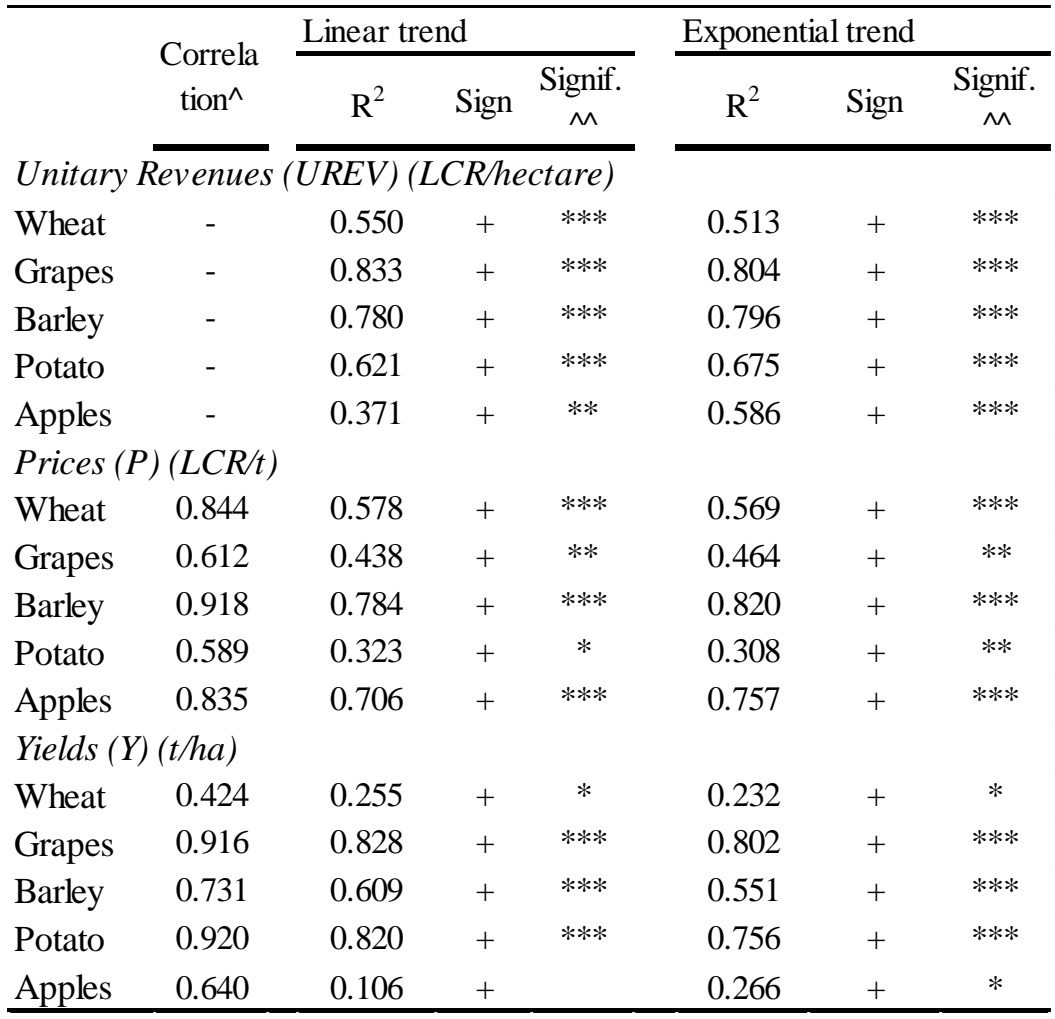

Source: Own elaboration on FAOSTAT data.

A part of the analysis is aimed at assessing the relative contribution of each crop to the variability of the revenues of the whole crop sector in Armenia. However, before doing so, it is important to stress that the variability of the revenues of the overall revenue deriving from the whole crop sector is limited: when revenue data are only deflated, the CV is approximately 0.25 . However, when data are adjusted also accounting for the evolution of productivity (either by using the trend of API or crop specific yields), the CV over the considered period range between 0.16 and 0.12 . This means that CV calculated on the original data are around three times higher than those calculated on data adjusted for trends in prices and productivity (i.e. around 0.38). This suggests to better focus the discussion of the results based on deflated and productivity adjusted data. Furthermore, it is important to note that, how it will be shown later, the variability of the revenues generated by single crops is way higher than the variability of the sum of the revenues from all crops as expected considering the pooling effect.

The relative contribution of each crop to the overall variability has been assessed by using the variance decomposition of additive components. Results of such decomposition show that a large share of it depends on the variability of the revenues from potatoes (between 26 and 49 per cent of the overall direct effects) and, to a lesser extent, on the variability of the residual crops, apples and wheat (Table 3).

However, the contribution of a specific crop depends not only on the variability of the revenues it generates, but also on the relative magnitude of its revenues in comparison to the revenues of the whole crop sector (i.e. Share of the revenues) as well as by the sign and extent of the correlation with the revenues of the other crops (i.e. interaction or covariance terms).

For example, the group Residual crops (accounting for all other crops apart the 5 considered major crops) generates a large relative direct effect but this is only because it accounts for around $2 / 3$ of the overall revenues. Thus, it is also important to compare the extent of direct effects with their shares that is the relative direct effects ( $\mathrm{p}_{\mathrm{i}} / \mathrm{Share}$ ). This suggests that apples, even accounting only for around 3 per cent of the revenues from all crops, contribute relatively way more than other crops to the variability of the revenues of the sector: the direct effect is more than 3 times higher than its share. Potatoes and wheat also generate a strong relatively direct effects. On the contrary, the contribution of the other crops is relatively lower than their shares (Table 3). 
Table 3. Contribution of each crop and of the residual crop group to the variability of revenues from the whole crop sector in Armenia. Direct effects $\left(\mathrm{p}_{\mathrm{i}}\right)$ and relative direct effects ( $\mathrm{p}_{\mathrm{i}} /$ Share). Years $2000-2013$.

\begin{tabular}{|c|c|c|c|c|c|c|c|}
\hline \multirow[b]{3}{*}{ Crops } & \multicolumn{3}{|c|}{ Direct effect $\left(\mathrm{p}_{\mathrm{i}}\right)$} & \multirow{2}{*}{$\begin{array}{l}\text { Share of } \\
\text { whole crop } \\
\text { revenues } \\
\text { (Share) }\end{array}$} & \multicolumn{3}{|c|}{$\begin{array}{l}\text { Relative direct effect } \\
\qquad\left(\mathrm{p}_{\mathrm{i}} / \text { Share }\right)\end{array}$} \\
\hline & $\mathrm{REV}^{\prime}$ & $\mathrm{REV}^{\prime} \mathrm{G}$ & REVC & & $\mathrm{REV}^{\prime}$ & REV'G & REVC \\
\hline & & & & & & & \\
\hline Apples & 0.0917 & 0.1526 & 0.1290 & $3.9 \%$ & 2.35 & 3.91 & 3.31 \\
\hline Barley & 0.0285 & 0.0284 & 0.0395 & $3.2 \%$ & 0.89 & 0.89 & 1.23 \\
\hline Grapes & 0.0829 & 0.0717 & 0.0554 & $7.1 \%$ & 1.17 & 1.01 & 0.78 \\
\hline Potatoes & 0.2568 & 0.3108 & 0.4858 & $14.0 \%$ & 1.83 & 2.22 & 3.47 \\
\hline Wheat & 0.0369 & 0.1369 & 0.0993 & $6.2 \%$ & 0.60 & 2.21 & 1.60 \\
\hline $\begin{array}{l}\text { Residual } \\
\text { crops }\end{array}$ & 0.5031 & 0.2996 & 0.1910 & $65.6 \%$ & 0.77 & 0.46 & 0.29 \\
\hline
\end{tabular}

Source: Own elaboration on FAOSTAT data.

The interaction terms, that account for the covariance between the considered crops, are generally very limited (Table 4). This is more the case when data are treated for trends provided that for many crops yields are all characterized by positive trends. It is important to mention that in most of the cases interaction terms are limited and positive.

Table 4. Interaction terms of the variance decomposition of the revenues from the whole crop sector in Armenia $\left(\mathrm{p}_{\mathrm{ij}}\right)$. Years $2000-2013$.

\begin{tabular}{lrrr}
\hline & \multicolumn{1}{c}{ REV' } & \multicolumn{1}{c}{ REV'G } & REVC \\
\cline { 2 - 4 } Interaction between: & & & \\
Apple-Barley & 0.009 & -0.006 & -0.030 \\
Apple-Grapes & 0.058 & 0.066 & 0.022 \\
Apple-Potatoes & 0.079 & 0.070 & 0.042 \\
Apple-Wheat & -0.023 & -0.071 & -0.043 \\
Apple-Residual & 0.136 & 0.123 & 0.028 \\
Barley-Grapes & 0.029 & 0.012 & -0.002 \\
Barley-Potatoes & 0.044 & 0.017 & 0.043 \\
Barley-Wheat & 0.013 & 0.013 & 0.055 \\
Barley-Residual & 0.083 & 0.035 & 0.016 \\
Grapes-Potatoes & 0.097 & 0.057 & 0.064 \\
Grapes-Wheat & -0.009 & -0.032 & 0.005 \\
Grapes-Residual & 0.185 & 0.115 & 0.055 \\
Potatoes-Wheat & -0.002 & 0.024 & 0.036 \\
Potatoes-Residual & 0.252 & 0.142 & 0.155 \\
Wheat-Residual & -0.027 & -0.077 & 0.011 \\
\cline { 2 - 4 } Sum of interaction terms & 0.926 & 0.489 & 0.457 \\
\hline
\end{tabular}

Source: Own elaboration on FAOSTAT data.

In the few cases in which these are negative (i.e. 3 when trends in yields ae accounted for), these are very close to zero. This suggests that there is limited scope for using production diversification to reduce the overall variability of the revenues from the crop sector.

The extent of the variability of the unitary revenues of the considered crops (UREV) has also been assessed. This strongly depends on whether trends in productivity are accounted for. In particular, accounting for such trends reduces $\mathrm{CV}$ levels (Table 5). Adjusting yield series by mean of API (UREV' ${ }_{\mathrm{G}}$ ) already allows for relevant reductions of CV levels in comparison with CV calculated on just deflated series (UREV'). Furthermore, using crop specific yield trends $\left(\mathrm{UREV}^{\prime}{ }_{\mathrm{C}}\right.$ and $\mathrm{UREV}_{\mathrm{C}}$ ) does not allow an additional relevant reduction of CV but in few cases (Table 5).

However, unitary revenues are rather variable also when trends in prices and yields are accounted for. The lowest values are always above 0.12 reaching a value of 0.65 in the case of apples. Indeed, the $\mathrm{CV}$ of the revenues from this latter crop is from 2.6 to 4.4 times higher than the one experienced by the aggregate of all crops. The other considered single crops have relatively lower levels of $\mathrm{CV}$ even if these are always higher than the variability of the revenues from the whole sector. Finally, the variability of unitary revenues for the aggregate "Residual crops" is way smaller than in the case of all other considered single crops and very much in line with the variability of the revenues for the aggregate crop sector (Table 5) as expected considering the pooling effect. 
Table 5. Variability of unitary revenues for the considered crops and for the revenues from the whole crop sector. Coefficient of Variation (CV) calculated over the years $2000-2013$.

\begin{tabular}{crrrcr}
\hline & UREV & UREV' & UREV'G & UREV'c & UREVC \\
Total Crops & 0.381 & 0.247 & 0.148 & n.a. & 0.125 \\
Apples & 0.621 & 0.642 & 0.650 & 0.471 & 0.492 \\
Barley & 0.551 & 0.394 & 0.282 & 0.333 & 0.258 \\
Grapes & 0.410 & 0.305 & 0.232 & 0.280 & 0.167 \\
Potatoes & 0.449 & 0.322 & 0.256 & 0.313 & 0.276 \\
Wheat & 0.357 & 0.220 & 0.243 & 0.136 & 0.240 \\
Residual crops & 0.343 & 0.216 & 0.142 & n.a. & 0.114 \\
\hline
\end{tabular}

Source: Own elaboration on FAOSTAT data.

The variance decomposition by multiplicative components ( $\mathrm{P}$ and $\mathrm{Y}$ ) has provided insights regarding the relative contribution of prices and yields to the variability of the unitary revenues of the considered crops. The results of this analysis allows to draw considerations that are relevant from a methodological point of view and from a policy oriented perspective.

From a methodological point of view, the main results are that accounting for trends in productivity allows to reduce the levels of the relative errors of the approximation in the decomposition procedure. This is fully consistent with the findings by Burt and Finley (1968). In particular, the use of API to adjust yield series already allows for relevant reductions of such errors (Table 6).

Regarding the way trends in yields are accounted for, results suggest that using crop specific trends does not allow a further relevant reduction of error levels (in comparison with UREV' ${ }_{\mathrm{G}}$ ) and can even result in an increase of these at least in a few cases (Table 6). However, it is important to stress that in some cases the way productivity trends are accounted for changes the relative importance of prices and yields in determining the variability of UREV. In particular, in wheat and grapes, using crops specific trends (UREV' ${ }_{\mathrm{C}}$ ) reverses the relative importance of prices and yields if compared with the results regarding UREV' ${ }_{\mathrm{G}}$. Finally, it is important to note that the level of the interaction terms $\left(\mathrm{p}_{12}\right)$ is very much affected by how data are treated.

These evidences suggest that accounting for trends in productivity is needed even to reduce the error level arising from the approximation of the decomposition procedure. Furthermore, results seem to suggest that accounting for a general trend of productivity is a reasonable way to do so.

Empirical results have shown that both prices and yields can strongly contribute to the variability of unitary revenues and that their relative importance changes according to the considered crop. In particular, in three crops over five (Apples, barley and wheat), yields $\left(\mathrm{p}_{2}\right)$ contribute more than prices $\left(\mathrm{p}_{1}\right)$ to the overall variability. The opposite can be said about grapes and potatoes. Unfortunately, in the cases of wheat and grapes results based on UREV' ${ }_{C}$ provide a completely different picture regarding the relative contribution of prices and yields (Table 6). However, in case of grapes the error term becomes way larger using UREV' ${ }_{\mathrm{C}}$ than when UREV' ${ }_{\mathrm{G}}$ is used. Thus, in this case it seems better to relay on the results regarding this latter revenue indicator.

Table 6. Variance decomposition of unitary revenues by price $\left(\mathrm{p}_{1}\right)$ and yield $\left(\mathrm{p}_{2}\right)$ components: direct and interaction effects $\left(\mathrm{p}_{12}\right)$, approximation error levels in the five considered crops in Armenia. Years $2000-2012$.

\begin{tabular}{|c|c|c|c|c|}
\hline & & UREV' & UREV' $_{G}$ & UREV'$^{\prime}{ }_{C}$ \\
\hline \multirow{4}{*}{ Apples } & $\mathrm{p}_{1}$ & $13 \%$ & $13 \%$ & $36 \%$ \\
\hline & $\mathrm{p}_{2}$ & $87 \%$ & $87 \%$ & $64 \%$ \\
\hline & $\mathrm{p}_{12}$ & $8 \%$ & $3 \%$ & $49 \%$ \\
\hline & Error & $10 \%$ & $5 \%$ & $4 \%$ \\
\hline \multirow{4}{*}{ Barley } & $\mathrm{p}_{1}$ & $10 \%$ & $16 \%$ & $15 \%$ \\
\hline & $\mathrm{p}_{2}$ & $90 \%$ & $84 \%$ & $85 \%$ \\
\hline & $\mathrm{p}_{12}$ & $12 \%$ & $-1 \%$ & $29 \%$ \\
\hline & Error & $7 \%$ & $5 \%$ & $4 \%$ \\
\hline \multirow{4}{*}{ Grapes } & $\mathrm{p}_{1}$ & $37 \%$ & $69 \%$ & $42 \%$ \\
\hline & $\mathrm{p}_{2}$ & $63 \%$ & $31 \%$ & $58 \%$ \\
\hline & $\mathrm{p}_{12}$ & $-8 \%$ & $-11 \%$ & $-3 \%$ \\
\hline & Error & $14 \%$ & $4 \%$ & $22 \%$ \\
\hline \multirow{4}{*}{ Potatoes } & $\mathrm{p}_{1}$ & $53 \%$ & $82 \%$ & $58 \%$ \\
\hline & $\mathrm{p}_{2}$ & $47 \%$ & $18 \%$ & $42 \%$ \\
\hline & $\mathrm{p}_{12}$ & $-4 \%$ & $0 \%$ & $-3 \%$ \\
\hline & Error & $8 \%$ & $1 \%$ & $10 \%$ \\
\hline \multirow{4}{*}{ Wheat } & $\mathrm{p}_{1}$ & $31 \%$ & $28 \%$ & $64 \%$ \\
\hline & $\mathrm{p}_{2}$ & $69 \%$ & $72 \%$ & $36 \%$ \\
\hline & $\mathrm{p}_{12}$ & $10 \%$ & $23 \%$ & $-16 \%$ \\
\hline & Error & $1 \%$ & $4 \%$ & $1 \%$ \\
\hline
\end{tabular}

Source: Own elaboration on FAOSTAT data. 


\section{Discussion}

The analysis has shown that farm revenues from single crop productions are variable even when series are adjusted for trends in prices and productivity.

Apples and, to a lesser extent, barley and potatoes, are the crops responsible for most of the variability of the revenues from the whole crop sector in Armenia. The variance decomposition has shown that both prices and yields can be both important in generating the variability of unitary revenues of the analyzed crops. Prices are the most important component causing revenue variability in two of these crops, while yields in the other three crops. Finally, the analysis does not support the hypothesis that a relevant natural hedge exists in the considered crops in Armenia but in grapes.

These results provid policy oriented insights and recommendations regarding the need to intervene to support risk management, how to target policy interventions where these are more needed and which tools can be used in those cases. Because of the assessed variability levels are not negligible, it is possible that revenue risk could be in some crop productions large enough to constrain investment in the farm sector and to justify the introduction of policies supporting the use of risk management tools in the Armenian farm sector. Most of the attention should be paid to producers of apples and, to a lesser extent, barley and potatoes because the revenues of these crops have the highest variability.

The tools to be used for risk management should vary according to the considered crops. Because of the differences in the relevance of the two considered sources of revenue variability, the tools to be used should differ between crops. Results suggest that there is scope for tools to specifically cope with yield uncertainty (e.g. insurances) in the case of apples, barley and wheat. On the contrary, in the case of grapes and potatoes it seems more important to rely on tools to manage price risk.

Finally, the analysis has also provided some results that are interesting from a methodological point of view not just in the case of Armenia, but even of other transitions economies because these face similar conditions (in terms of market and productivity evolutions) and need to better manage farm risk. Trends in prices and yields should be accounted for when analyzing revenue variability because significant positive trends in both prices and productivity have been found.

The choice of whether and how to account for such trends is relevant because it affects both the assessed level of variability and the results of the variance decomposition. The results of the empirical analysis suggest that deflating prices and using a general agricultural productivity index could be enough to get sound results regarding level and sources of farm revenue risks. Adjusting the original yield series by mean of the API could be appropriate in most of the cases even if crop specific trends should also be estimated and tested in empirical analyses. However, this latter approach relies on the strong hypothesis that producers are able to predict the long-term evolution of crop specific yields. Thus, it is not possible to say whether this specific approach could be used in other circumstances/countries. In particular, in order to decide about this important choice, it is suggested to consider the level of correlation between the general agricultural productivity index and the single crop yields, and whether significant and heterogeneous crop specific crop trends exist. Finally, it is advisable to verify the resulting level of variability and the approximation resulting from the variance decomposition approach after any data transformation.

\section{References}

Baffes, J., \& Haniotis, T. (2010). Placing the 2006/08 commodity price boom into perspective. Working Paper Series Policy Research Working Papers. World Bank. Washington, DC, August 2010. http://dx.doi.org/10.1596/1813-9450-5371

Bobojonov, I., \& Götz, L. (2015). Pros and cons of subsidizing agricultural insurance programs in the CIS. Paper presented at the IAMO Forum: 'Agriculture and Climate Change in Transition Economies', Halle (Saale), Germany, 17-19.

Bohrnstedt, G. W., \& Goldberger, A. S. (1969). On the exact covariance of products of random variables. Journal of the American Statistical Association, 64(328), 1439-1442.

Burt, O. R., \& Finley, R. M. (1968). Statistical analysis of identities in random variables. American Journal of Agricultural Economics, 50(3), 734-744.

El Benni, N., \& Finger, R. (2013). Gross revenue risk in Swiss dairy farming. Journal of Dairy Science, 96, 936-948. http://dx.doi.org/10.3168/jds.2012-5695 FAOSTAT Agricultural production indices. http://faostat3.fao.org/mes/methodology_list/E

Goodman, L. A. (1960). On the exact variance of products. Journal of the American Statistical Association, 55(292), 708-713.

Hadrich, J. C. (2013). Quantifying the sources of revenue variation in the Northern Great Plains. Agricultural Finance Review, 73(3), 493-505. http://dx.doi.org/10.1108/AFR-09-2012-0046 
Hardaker, J. B., Huirne, R. B. M., Anderson, J. R., \& Lien, G. (2004). Coping with Risk in Agriculture. Second Edition. Wallingford, Oxforshire OX10 8DE, UK: CABI Publishing.

Isakson, S. R. (2015). Derivatives for Development? Small-Farmer Vulnerability and the Financialization of Climate Risk Management. Journal of Agrarian Change, 15(4), 569-580. http://dx.doi.org/10.1111/joac.12124

Kannan, E. (2015). Trends in Agricultural Incomes: An Analysis at the Select Crop and State Levels in India. Journal of Agrarian Change, 15, 201-219. http://dx.doi.org/10.1111/joac.12068

Mishra, A. K., \& El-Osta, H. S. (2001). A temporal comparison of sources of variability in farm household income. Agricultural Financial Review, 61(2), 181-198. http://dx.doi.org/10.1108/00214820180001123

Mishra, A. K., \& Sandretto, C. L. (2002). Stability of farm income and role of nonfarm income in U.S. agriculture. Review of Agricultural Economics, 24(1), 208-221. http://dx.doi.org/10.2307/1349829

Muradullaev, N. N., Bobojonov, I., Aw-Hassan, A., \& Glauben, T. (2015). Demand for crop insurance in Uzbekistan. Paper presented at the IAMO Forum: 'Agriculture and Climate Change in Transition Economies', Halle (Saale), Germany, 17-19.

OECD (2009). Managing risk in agriculture. A holistic approach. Paris, France: OECD publication.

Offutt, S. E., \& Blandford, D. (1986). Commodity market instability. Empirical techniques for analysis. Resource Policy, 12(1), 62-72.

Wolf, C. A., Black, J. R., \& Hadrich, J. C. (2009). Upper Midwest dairy farm revenue variation and insurance implications. Agricultural Finance Review, 69(3), 346-358. http://dx.doi.org/10.1108/00021460911002716

\section{Notes}

Note 1. Following Offutt \& Bladford (1987), data has been detrend only when the coefficient of multiple correlation $\left(\mathrm{R}^{2}\right)$ is higher than 0.6. If the $\mathrm{R}^{2}$ of both linear and exponential trends exceed 0.6 , the one with the higher $\mathrm{R}^{2}$ has been used.

\section{(cc) $\mathrm{BY}$}

This work is licensed under a Creative Commons Attribution 3.0 License. 